\title{
Determination of Anthracycline Drug Residual in Cleaning Validation Swabs of Stainless-Steel Equipment after Production of Cytostatic Injections Using HPLC Analytical Method
}

\author{
Zuzana Slivová $^{1}$ and Radka Opatřilová ${ }^{2}$ \\ ${ }^{1}$ oncomed manufacturing a.s., Karásek 1229/1b, 62100 Brno, Czech Republic \\ ${ }^{2}$ Department of Chemical Drugs, Faculty of Pharmacy, University of Veterinary and Pharmaceutical Sciences Brno, \\ Palackého 1-3, 61242 Brno, Czech Republic
}

Correspondence should be addressed to Zuzana Slivová; slivova.zu@gmail.com

Received 9 May 2015; Revised 24 June 2015; Accepted 25 June 2015

Academic Editor: Jeongkwon Kim

Copyright (C) 2015 Z. Slivová and R. Opatřilová. This is an open access article distributed under the Creative Commons Attribution License, which permits unrestricted use, distribution, and reproduction in any medium, provided the original work is properly cited.

\begin{abstract}
Standard cleaning procedures of production line equipment were verified after manufacture of cytostatic injections containing Anthracycline derivate substance. Residual content of Anthracycline drug substance on stainless-steel equipment surface was determined using swab sampling with a specific HPLC-DAD analysis. The acceptance limit was decided as $200.0 \mu \mathrm{g} / 100 \mathrm{~cm}^{2}$. Recovery from the stainless-steel surface was $90.1 \%$. Linearity of the method was observed in the concentration range of $0.155-$ $194 \mu \mathrm{g} / \mathrm{mL}$ when estimated using Zorbax TMS $(5 \mu \mathrm{m}, 0.25 \mathrm{~m} \times 4.6 \mathrm{~mm}$ ID) column at $1.3 \mathrm{~mL} / \mathrm{min}$ flow rate and $254 \mathrm{~nm}$ (DAD 190-600 nm). The mobile phase consisted of lauryl hydrogen sulphate solution $(3.7 \mathrm{~g} / \mathrm{L}):$ methanol : acetonitrile $(54: 16: 30$, v/v/v) with $\mathrm{pH}$ adjusted to 2.5 using phosphoric acid (85\%). The LOD and LOQ for Anthracycline derivate were found to be 0.047 and $0.155 \mu \mathrm{g} / \mathrm{mL}$, respectively. The method validation confirmed the method provides acceptable degree of selectivity, linearity, accuracy, and precision for the intended purposes.
\end{abstract}

\section{Introduction}

Cleaning validation plays an important role in prevention of cross contamination of consecutively manufactured drug products. The main goal of cleaning validation is to verify the effectiveness of cleaning procedures and to ensure no risks are associated with cross contamination of active ingredients or detergent/sanitizer. Cleaning may be defined as a removal of residues and contaminants are removed from the equipment. The residues and contaminants can be the products themselves manufactured in the equipment or residues originating from the cleaning procedure (detergents/sanitizers) or degradation products resulting from the cleaning process itself. Cleaning validation is not performed only to satisfy regulatory authorities. The safety of patients is the primary objective, and product contamination presents serious liability issues for any pharmaceutical manufacturer or contract organization. The cleaning validation involves identification of numerous sampling points in the manufacturing line to demonstrate complete removal of residues and determination of acceptance limits for residues. Currently, the acceptance limits for residues are not established by the regulatory authorities, but decision requires logical and scientific justification in the limits determination.

The limit for maximum accepted contamination of the next product by active pharmaceutical ingredient (Maximum Allowable Carryover, MAC) is calculated using mathematical formulae considering therapeutic doses and toxicological profiles of the ingredients. Generally, there are three basic approaches in determining the acceptance limits for cleaning validation [1]. Approach 1 is based on the dose criterion, where not more than 0.001 of minimum daily dose of any product will appear in the maximum daily dose of the next product. Approach 2 involves $10 \mathrm{ppm}$ criterion, where any active ingredient can be present in a subsequently manufactured product at a maximum level of $10 \mathrm{ppm}$. Approach 
3 is visually clean criterion, where no quantity of residue should be visible on the equipment after cleaning procedures are performed. The three criteria suggested by Fourman and Mullen were adopted by many regulatory guidelines: PDA 1998 TR 29 Guideline, PIC/S 2007 Guideline (European), CEFIC/APIC 2000 Guideline (European), TPP 2008 CV Guidelines (Health Canada), and WHO Guide to GMPs TRS 9372006 [2-6]. According to FDA's requirement, the rationale for the residue limits should be logical based on the knowledge of the materials involved and should be practical, achievable, and verifiable. The basis of any limits should be scientifically justifiable [7].

Usage of the safety factor in the acceptance limits calculation may be appropriate especially in case of the products with low therapeutic index. The choice of the safety factor value depends on the dosage form of the product. The safety factor recommended for injectable products is $1 / 1000$ th to $1 / 10,000$ th of a normal daily dose [2].

Anthracyclines belong to antitumor antibiotics. Originally, they were used for the therapy of infectious diseases. Besides the antibiotic effect, the immunosuppressive, cytostatic, antitumor, and antiproliferative effects were observed in some of these substances. Anthracyclines exert their cytostatic action through four major mechanisms: (1) inhibition of topoisomerase II, (2) high-affinity binding to DNA through intercalation, with consequent blockade of the synthesis of DNA and RNA and DNA strand scission, (3) generation of semiquinone free radicals and oxygen free radicals through an iron-dependent, enzyme-mediated reductive process, and (4) binding to cellular membranes to alert fluidity and ion transport [8]. While the precise mechanism by which Anthracyclines exert their cytotoxic effects remains to be defined (and may depend on the specific tumor type), it is now well established that free radical mechanism is the cause of the cardiotoxicity associated with Anthracyclines [811]. The basis of the chemical structure consists of tetracene skeleton with pyran ring bonded by oxygen. The molecule has a chromophore group causing Anthracyclines to be red coloured powders [12]. The differences between particular Anthracycline drugs are related to the structure of aglycone or hydrocarbon part of the molecule (Figure 1) $[13,14]$.

In this paper, effectiveness of standard cleaning procedures of manufacturing equipment was verified after production of cytostatic injections containing Anthracycline derivate API (active pharmaceutical ingredient) by swabbing of the residuals from the stainless-steel equipment surface. The aim of the paper was to provide a validated method for Anthracycline drug substance residuals determination in swabs.

\section{Materials and Methods}

2.1. Instruments and Chemicals. The analysis was performed at analytical laboratory of oncomed manufacturing a.s. An HPLC system DIONEX Ultra 3000, software DIONEX CHROMELEON version 6.8, and balances Mettler Toledo XP26 and XS802S were used for the analytical method validation and swab samples analysis. The following chemicals were used: sodium dodecyl hydrogen sulphate (Merck), phosphoric acid (Lach-Ner), acetonitrile (Sigma-Aldrich), methanol (Sigma-Aldrich), and formic acid (Sigma-Aldrich). Water for injection was produced by oncomed manufacturing a.s. All chemicals used were of analytical reagent grade.

Reference standard of the Anthracycline drug derivate ( $96.4 \%$ as is) was provided by oncomed manufacturing a.s.

Equipment of oncomed manufacturing a.s. production line 1 was swabbed using Alpha Swabs after production of the drug product containing Anthracycline derivate API.

\subsection{Method Description}

2.2.1. Chromatographic Conditions. Chromatographic conditions were as follows:

(i) Column: Zorbax TMS $(5 \mu \mathrm{m}), 250 \mathrm{~mm} \times 4.6 \mathrm{~mm}$ ID.

(ii) Column temperature: $35^{\circ} \mathrm{C}$.

(iii) Flow rate: $1.3 \mathrm{~mL} / \mathrm{min}$.

(iv) Injection: $40 \mu \mathrm{L}$.

(v) Detection: $254 \mathrm{~nm}$, DAD 190-600 nm.

(vi) Run time: 20 minutes.

(vii) Sample temperature: $5^{\circ} \mathrm{C}$.

The mobile phase was prepared by mixing of $540 \mathrm{~mL}$ of sodium lauryl hydrogen sulphate $(3.7 \mathrm{~g} / \mathrm{L})$ solution with $160 \mathrm{~mL}$ of methanol and $300 \mathrm{~mL}$ of acetonitrile. Mobile phase $\mathrm{pH}$ was adjusted to 2.5 using phosphoric acid (85\%). The mobile phase was filtered through $0.45 \mu \mathrm{m}$ nylon membrane filter.

The stock solution of standard was prepared by dissolving of $10.0 \mathrm{mg}$ ANTd RS in diluent to get $100.0 \mathrm{~mL}$ of the solution. Consequently, $1.0 \mathrm{~mL}$ of the stock solution was diluted in diluent up to $50.0 \mathrm{~mL}$ getting reference solution with concentration $2 \mu \mathrm{g} / \mathrm{mL}$ of ANTd.

2.2.2. Sample Solution. Diluent consisted of methanol and water in volume ratio $1: 1$ with $\mathrm{pH}$ adjusted to 2.5 using formic acid. An Alpha Swab textile was immersed into the clean sample container containing $8 \mathrm{~mL}$ of diluent. Surface of $10 \times$ $10 \mathrm{~cm}$ was wiped off in one direction. Afterwards the Alpha Swab textile was immersed into the sample container with diluent again and drained away and the same surface was wiped off in perpendicular direction. Subsequently, the Alpha Swab was putted into the sample container with diluent. The container was closed and the extraction was performed using ultrasonic bath for 5 minutes. The liquid was quantitatively transferred into a $10 \mathrm{~mL}$ amber glass volumetric flask. The used Alpha Swab was drained into the same flask and the volume was filled up to the mark with diluent.

\section{Results and Discussion}

3.1. Acceptance Limit Calculation. The determination of cleaning limits and acceptance criteria is a crucial element of a good cleaning programme. Considering the pharmacological potency of the products, total surface area of all equipment, 
<smiles>COc1cccc2c1C(=O)c1c(O)c3c(c(O)c1C2=O)C[C@@](O)(C(=O)[C@@H](C)CO)C[C@H]3O[C@H]1C[C@H](N)[C@H](O)[C@H](C)O1</smiles><smiles></smiles>

DNR<smiles>COc1cccc2c1C(=O)c1c(O)c3c(c(O)c1C2=O)C[C@@](O)(C(=O)[14CH2]CO)C[C@H]3OC1CC(N)C(O)C1C</smiles>

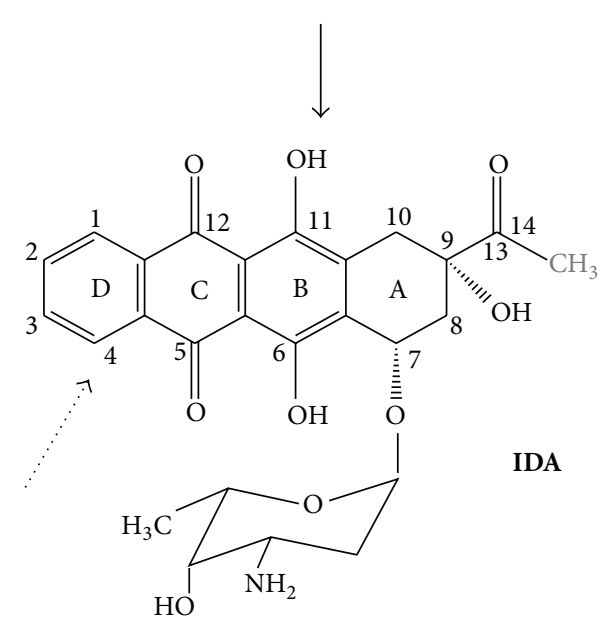

FIGURE 1: Chemical structures of main Anthracyclines: doxorubicin (adriamycin): DOX, daunorubicin: DNR, epirubicin: EPI, and idarubicin: IDA. The differences between drugs are marked by arrow.

swab area, and recovery factor of the limit for swab were calculated according to formulae (1) and (2) [15]. Consider

$$
\mathrm{MAC}=\frac{\mathrm{TD}}{\mathrm{SF}} \times \frac{\mathrm{BS}}{\mathrm{LDD}}[\mu \mathrm{g}]
$$

where TD is minimal therapeutic dose of the cleaned product; SF is safety factor $1 / 10,000$; BS is the smallest batch size of the next product; LDD is the largest daily dose of the next product. Consider

$$
\max C \text { per swab }=\frac{\mathrm{MAC} \times P_{S} \times R}{P_{A}}\left[\mu \mathrm{g} / 100 \mathrm{~cm}^{2}\right],
$$

where $P_{S}$ is swab surface area $\left(100 \mathrm{~cm}^{2}\right), P_{A}$ is surface area of all equipment $\left(\mathrm{cm}^{2}\right)$, and $R$ is theoretical recovery factor $(0.8)$.

The acceptance limit was decided as $200.0 \mu \mathrm{g}$ per swab $100 \mathrm{~cm}^{2}$.

3.2. Method Validation. The general procedure of the analytical method validation was in accordance with the ICHGuideline Q2(R1) [16]. The analytical method was validated to prove that it provides acceptable degree of selectivity, linearity, accuracy, and precision for the intended purposes. Within the validation method's quantification and detection limits were established together with recovery factor for stainless-steel material.
3.2.1. System Suitability Test. Relative standard deviation (RSD) of the peak areas, calculated from repeated injections of the same preparation of reference solution, was $<2.0 \%$. Relative standard deviation (RSD) of the peak retention times, calculated from 6 repeated consecutive injections of the same preparation of reference solution, was $<1.0 \%$. Retention time of the peak was within $12 \pm 1 \mathrm{~min}$. Tailing factor of the peak was within the range from 0.8 to 1.5 . Signalto-noise ratio of the peak was $>10$.

3.2.2. Selectivity. For the specificity of the method verification, four solutions were measured:

(1) Diluent $=$ blank for swabs.

(2) Reference solution $(2 \mu \mathrm{g} / \mathrm{mL})$.

(3) Extract of a pure Alpha Swab.

(4) Swab of pure stainless-steel material.

No interfere peaks were detected in diluent, extract of a pure Alpha Swab, or swabs of pure stainless-steel material. Corresponding chromatograms are shown in Figures 2, 3, 4, and 5.

3.2.3. Linearity. Six solutions of ANTd RS were analysed at six different concentration levels ranging from 0.155 (LOQ) 


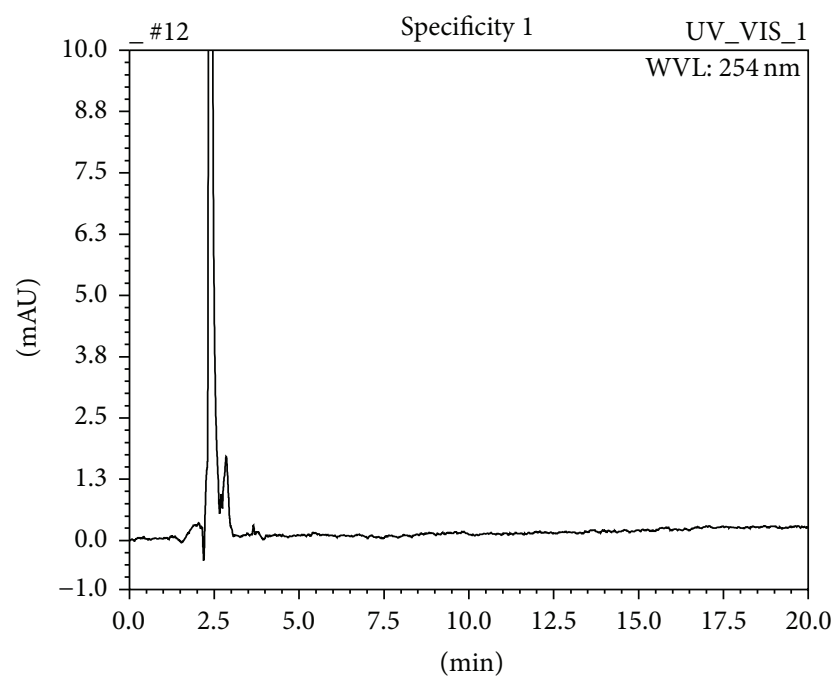

Figure 2: Blank for swabs (diluent).

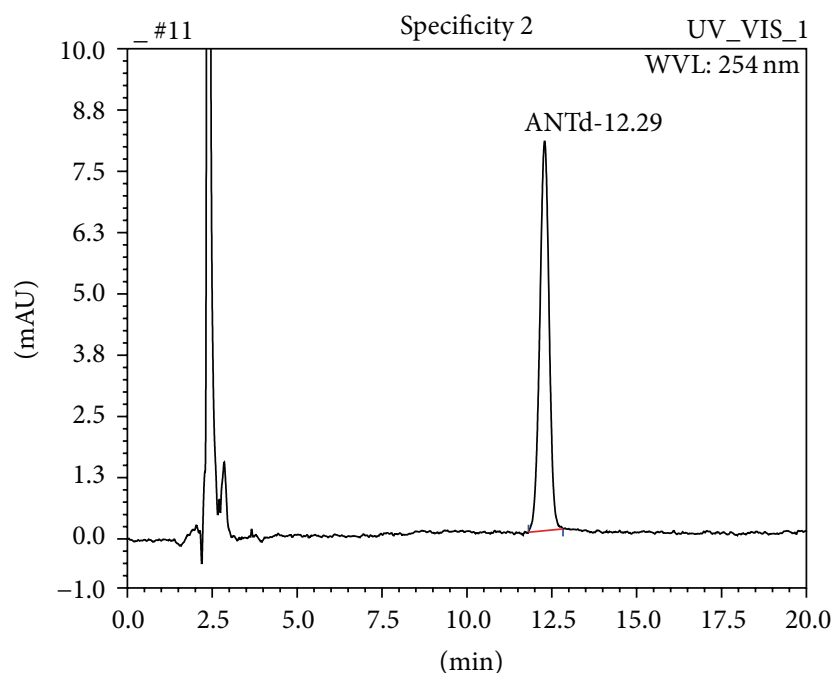

FIgURE 3: Reference solution $(2 \mu \mathrm{g} / \mathrm{mL})$.

to $193.552 \mu \mathrm{g} / \mathrm{mL}$. Each of them was injected three times. Linearity was observed when mean response area was plotted against concentration, using the least square and regression method (Figures 6 and 7 and Table 1).

3.2.4. Precision/Repeatability. Stainless-steel surface was contaminated by known amount of ANTd six times $\left(2.8 \mu \mathrm{g} / 100 \mathrm{~cm}^{2}\right)$. Consequently, the surface was wiped off and sample solution from the swab was prepared and analysed. The degree of method's precision/repeatability was shown to be acceptable for cleaning validation purposes. Results are presented in Table 2.

3.2.5. Accuracy. Swab solutions from stainless-steel surface contaminated by concentration of ANTd RS ranging from LOQ to $29 \mu \mathrm{g} / \mathrm{mL}$ were analysed. Determined recoveries are displayed in Table 3.

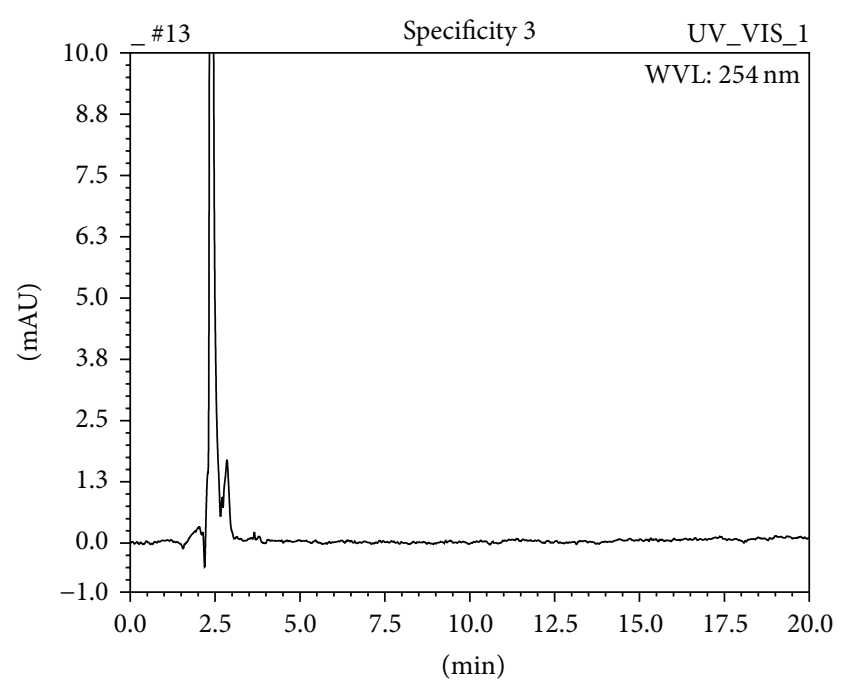

FIgURE 4: Extract of a pure Alpha Swab.

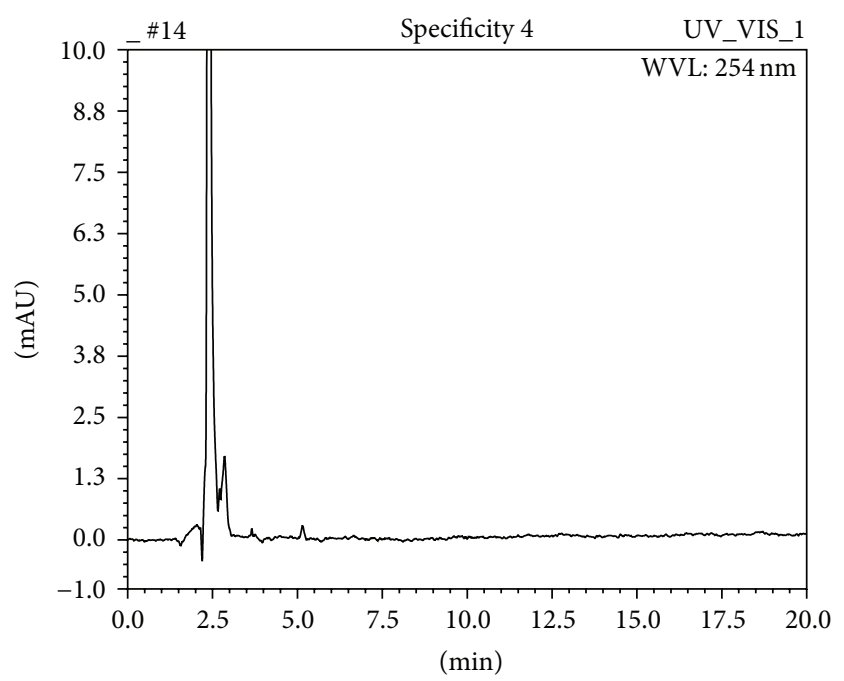

FIGURE 5: Swabs of pure stainless-steel material.

\subsubsection{Determination of Detection Limit (LOD) and Quantification Limit (LOQ)}

(1) LOQ. For method's quantification limit determination approximate LOQ was calculated first. The calculated LOQ was then practically verified.

(i) Calculation from Reference Solution ( $2 \mu \mathrm{g} / \mathrm{mL}$ ANTd RS). In the chromatogram of reference solution $(2 \mu \mathrm{g} / \mathrm{mL})$ signal-tonoise ratio of ANTd peak was measured. Assuming a linear response the corresponding concentration for $S / N=10$ was calculated to obtain approximate LOQ (Table 4).

(ii) Practical Verification. Results of practical verification of LOQ are shown in Table 5. 


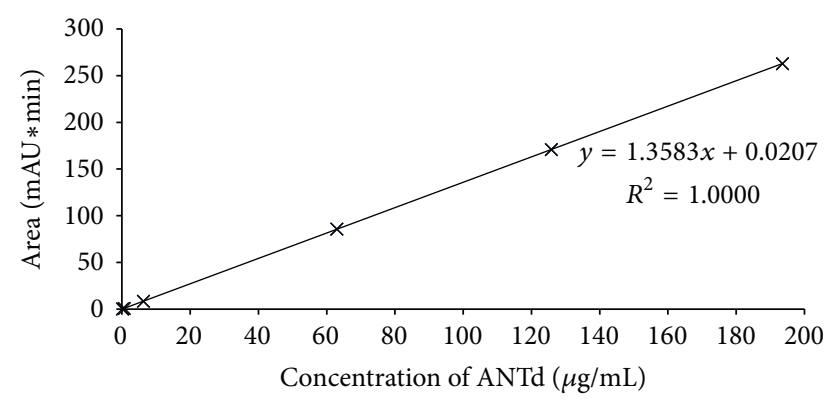

FIGURE 6: Linear regression.

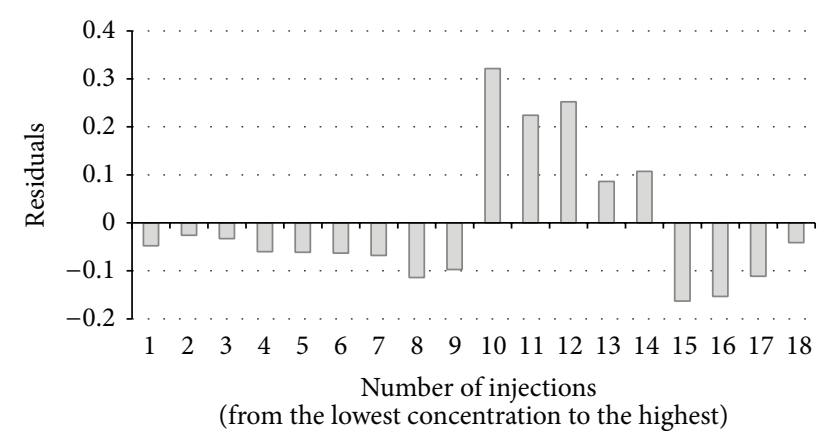

FIGURE 7: Linearity, residuals.

TABLE 1: Evaluation of method linearity.

\begin{tabular}{lc}
\hline Statistical parameter & Value \\
\hline Concentration range $(\mu \mathrm{g} / \mathrm{mL})$ & $0.155-193.552$ \\
$y$-intercept & 0.0207 \\
Slope & 1.3583 \\
Residual standard deviation & 0.146 \\
Confidence interval for $y$-intercept $(95 \%)$ & $0.0207 \pm 0.0978$ \\
\hline Correlation coefficient & 1.00 \\
Criterion of acceptance: correlation coefficient & $\geq 0.99$ \\
\hline
\end{tabular}

TABLE 2: Results of repeatability.

\begin{tabular}{lc}
\hline Solution preparation & ANTd content $(\mu \mathrm{g} / \mathrm{mL})$ \\
\hline 1 & 0.2264 \\
2 & 0.2152 \\
3 & 0.2683 \\
4 & 0.2663 \\
5 & 0.2774 \\
6 & 0.2712 \\
\hline RSD & $10.4 \%$ \\
Criterion of acceptance & RSD $\leq 15.0 \%$ \\
\hline
\end{tabular}

Figure 8 is the chromatogram of LOQ solution $(0.1554 \mu \mathrm{g} / \mathrm{mL})$.

\section{(2) $L O D$}

Verification of LOD. LOD solution was prepared by diluting of LOQ solution $(0.1554 \mu \mathrm{g} / \mathrm{mL}) 3 \mathrm{~mL} / 10 \mathrm{~mL}$ using the diluent.

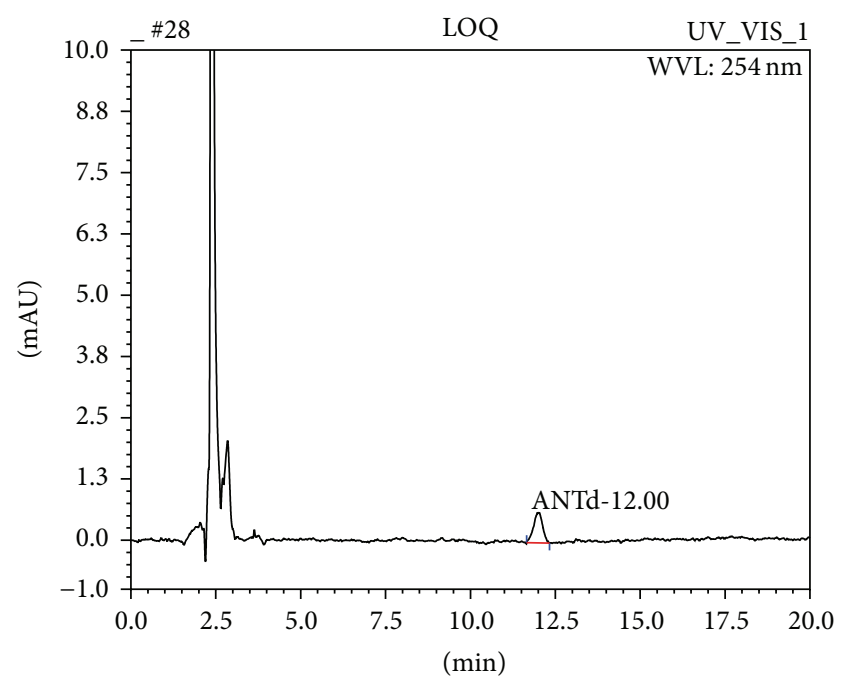

FIGURE 8: LOQ solution $(0.1554 \mu \mathrm{g} / \mathrm{mL})$.

The LOD solution was prepared once and injected six times. Measured signal-to-noise ratios of ANTd peaks are shown in Table 6.

Figure 9 is the chromatogram of LOD solution $(0.0466 \mu \mathrm{g} / \mathrm{mL})$.

3.2.7. Recovery Factor Determination. Recovery is the percentage of residual material that is actually removed by the sampling technique. Recovery for the stainless-steel surface was calculated using the results obtained during the precision test by formulae (3). Calculated recoveries are listed in Table 7. Consider

$$
R_{i}(\%)=\frac{100 \times m_{i}}{m_{0}},
$$

where $m_{0}$ is a known amount of ANTd sprayed on the surface equal to $0.28193 \mu \mathrm{g} / \mathrm{mL}$ and $m_{i}$ is a determined amount of ANTd.

3.2.8. Stability of Reference Solution. The stability of the reference solution was tested by storing of the solution at given temperature for 72 hours. The reference solution was prepared and stored always in amber glass, once exposed to daylight at $15-25^{\circ} \mathrm{C}$ and once in dark at $2-8^{\circ} \mathrm{C}$. The samples were injected after $4 \mathrm{~h}, 8 \mathrm{~h}, 12 \mathrm{~h}, 24 \mathrm{~h}, 48 \mathrm{~h}$, and $72 \mathrm{~h}$ against fresh reference standard solution. The stability of the reference solution $(2 \mu \mathrm{g} / \mathrm{mL})$ after 72 hours showed $<1 \%$ difference in results under both storage conditions, daylight at $15-25^{\circ} \mathrm{C}$ and dark at $2-8^{\circ} \mathrm{C}$.

3.3. Execution of Cleaning Validation. Swab samples were collected from different sampling points over the production line. Residual content of ANTd was determined in the samples. Results are shown in Table 8.

In this paper, cleanliness of the production line equipment after standard cleaning procedures after manufacturing of the drug product containing Anthracycline derivate 
TABLE 3: Results of accuracy/swabs of stainless steel.

\begin{tabular}{|c|c|c|c|}
\hline Solution & Accuracy, recovery $R_{i}(\%)$ & $\begin{array}{c}\text { Average recovery } \\
R(\%) \\
\end{array}$ & RSD (\%) \\
\hline LOQ $(0.155 \mu \mathrm{g}$ of ANTd/mL) & $\begin{array}{l}94.37 \\
98.05 \\
97.58 \\
\end{array}$ & 97 & 2.1 \\
\hline $0.27 \mu \mathrm{g}$ of $\mathrm{ANTd} / \mathrm{mL}$ & $\begin{array}{l}94.75 \\
94.42 \\
99.94\end{array}$ & 96 & 3.2 \\
\hline $19 \mu \mathrm{g}$ of $\mathrm{ANTd} / \mathrm{mL}$ & $\begin{array}{l}105.74 \\
106.35 \\
111.84 \\
\end{array}$ & 108 & 3.1 \\
\hline $29 \mu \mathrm{g}$ of $\mathrm{ANTd} / \mathrm{mL}$ & $\begin{array}{l}103.43 \\
107.65 \\
100.36\end{array}$ & 104 & 3.5 \\
\hline
\end{tabular}

Criterion of acceptance: average recovery $R$

Criterion of acceptance: RSD (i) LOQ concentration level: $80-120 \%$

(ii) Others: $85-115 \%$

$\leq 15.0 \%$
TABLE 4: Results: calculation of approximate LOQ.

\begin{tabular}{lc}
\hline Parameter & Value \\
\hline Weight of ANTd & $9.866 \mathrm{mg}$ \\
$\begin{array}{l}\text { Average } S / N \text { from } 2 \\
\text { injections of reference } \\
\text { solution }\end{array}$ & 128.6 \\
LOQ solution with $S / N=$ & $0.15 \mu \mathrm{g} / \mathrm{mL}$ of ANTd \\
10 & \\
\hline
\end{tabular}

TABLE 5: Results: practical verification of LOQ.

\begin{tabular}{lcc}
\hline Solution & $S / N$ & $\begin{array}{c}\text { Areas } \\
(\mathrm{mAU} * \min )\end{array}$ \\
\hline & 13 & 0.199 \\
& 10 & 0.191 \\
LOQ solution $(0.1554 \mu \mathrm{g} / \mathrm{mL})$ & 11 & 0.192 \\
& 13 & 0.206 \\
& 11 & 0.191 \\
RSD & 12 & 0.220 \\
Criterion of acceptance $S / N$ & - & $5.8 \%$ \\
Criterion of acceptance RSD & - & - \\
Criterion of acceptance LOQ & \multicolumn{2}{c}{$\leq 0.28 \mu \mathrm{g} / \mathrm{mL}$} \\
\hline
\end{tabular}

substance was verified. The equipment surface was sampled by swabbing technique. The acceptance limit for ANTd was decided as $200.0 \mu \mathrm{g}$ per swab (area of $100 \mathrm{~cm}^{2}$ ) considering the pharmacological potency of the cleaned and following product, total surface of all shared equipment, swab area, and recovery factor. Collected swabs were analysed using validated HPLC-DAD method. Content of Anthracycline drug substance was determined below the analytical method LOQ or LOD in all swab samples. Comparison of obtained residual concentrations and determined cleaning limit shows that standard cleaning procedures provide high margin of
TABLE 6: Results: practical verification of LOD.

\begin{tabular}{lc}
\hline Solution & $S / N$ \\
\hline & 4 \\
LOD solution $(0.0466 \mu \mathrm{g} / \mathrm{mL})$ & 4 \\
& 4 \\
& 4 \\
Criterion of acceptance & 4 \\
\hline
\end{tabular}

TABLE 7: Results of recovery.

\begin{tabular}{lc}
\hline Solution preparation & Recovery $R_{i}(\%)$ \\
\hline 1 & 80.30 \\
2 & 76.33 \\
3 & 95.16 \\
4 & 94.46 \\
5 & 98.39 \\
6 & 96.19 \\
\hline Average recovery $R$ & $90.1 \%$ \\
Criterion of acceptance: & $\geq 70.0 \%$ \\
average recovery $R$ &
\end{tabular}

safety and sufficiently remove Anthracycline residues below maximum permitted concentration from the tested equipment.

Validation of HPLC-DAD analytical method was performed prior to cleaning validation and confirmed its suitability for residual content of ANTd determination in swab samples. Linearity of the method was observed within the concentration range of $0.155-194 \mu \mathrm{g} / \mathrm{mL}$ with correlation coefficient 1.00. Recovery from the stainless-steel material was $90.1 \%$. The LOD and LOQ for the tested substance were found to be 0.047 and $0.155 \mu \mathrm{g} / \mathrm{mL}$, respectively. The method provides acceptable degree of selectivity, precision, 
TABLE 8: Results of swabs analysis sampled from the stainless-steel formulation vessel and filling machine and product pipeline.

\begin{tabular}{lcc}
\hline Equipment & Sampling point & Residual conc. $(\mu \mathrm{g} / \mathrm{mL})$ \\
\hline & Formulation vessel's bottom close to the stirrer & $<$ LOD \\
Formulation vessel & Discharge pipe from the vessel & $<$ LOD \\
& Internal part of the large neck & $<$ LOQ \\
\hline & Inlet into filling machine & $<$ LOD \\
Filling machine and product pipeline & Internal filling pump part & $<$ LOD \\
& Internal surface from the second filter housing & $<$ LOD \\
\hline
\end{tabular}

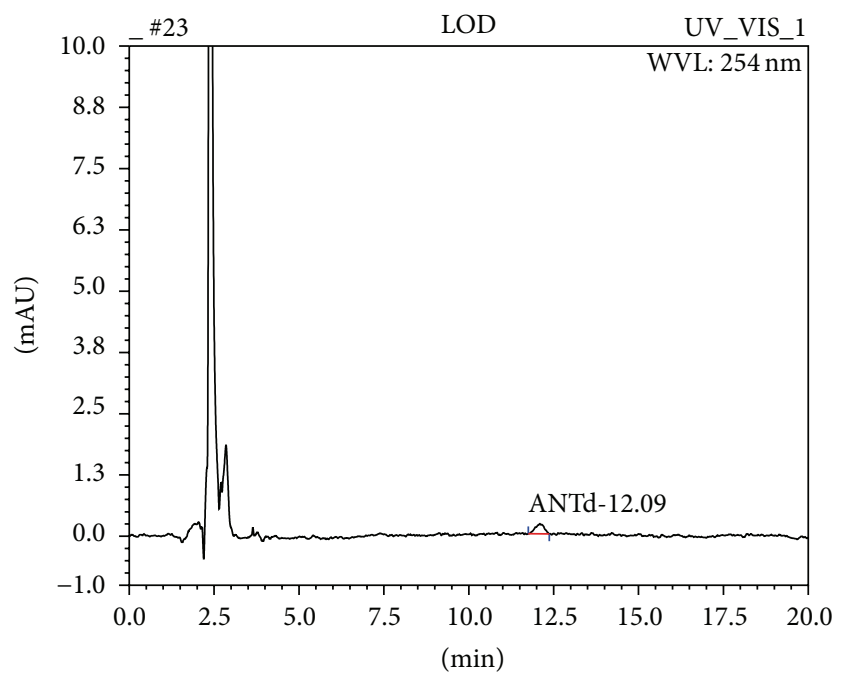

FIGURE 9: LOD solution $(0.0466 \mu \mathrm{g} / \mathrm{mL})$.

linearity, and accuracy for intended purposes. The HPLCDAD method was successfully included in the multiproduct facility cleaning validation programme. As an integral part of the cleaning validation, the method is important for the manufacture.

\section{Conclusion}

Swab samples were collected from stainless-steel surfaces of production equipment and were evaluated by specific HPLC analytical method for Anthracycline drug residual determination to demonstrate the cleaning procedures' effectiveness. All samples met established acceptance criterion. Complying results show that set cleaning procedures are reproducible, effective, and sufficient to remove tested Anthracycline derivate below the values of the maximum permitted contamination from all tested equipment. Prior to cleaning validation the analytical method was validated. The analytical method was found to be selective, precise, accurate, and linear. It was proven that HPLC-DAD method was suitable for intended purpose.

\section{Conflict of Interests}

The authors declare that there is no conflict of interests regarding the publication of this paper.

\section{Acknowledgments}

The experimental work was done by using the facilities of the company oncomed manufacturing a.s. The authors acknowledge the support of the experimental work by oncomed manufacturing a.s. Support of the Department of Chemical Drugs, Faculty of Pharmacy, University of Veterinary and Pharmaceutical Sciences, is gratefully acknowledged as well.

\section{References}

[1] G. Fourman and M. Mullen, "Determining cleaning validation acceptance limits for pharmaceutical manufacturing operations," Pharmaceutical Technology, vol. 17, no. 4, pp. 54-60, 1993.

[2] PDA, "Points to consider for cleaning validation," Tech. Rep. 29, 1998.

[3] Pharmaceutical Inspection Convention, "Recommendations on validation master plan, installation and operational qualification, non-sterile process validation, cleaning validation," Tech. Rep. PI 006-3, 2007.

[4] European Chemical Industry Council/Active Pharmaceutical Ingredients Committee, Guidance on Aspects of Cleaning Validation in Active Pharmaceutical Ingredient Plants, APIC, 2000.

[5] Health Products and Food Branch Inspectorate, Cleaning Validation Guidelines (GUIDE-0028), 2008.

[6] World Health Organization, "Appendix 3 cleaning validation in: annex 4 supplementary guidelines on good manufacturing practices: validation," Technical Report Series 937, World Health Organization, 2006.

[7] US Food and Drug Administration (FDA); Office of Regulatory Affairs, "Guide to inspections validation of cleaning processes 7/29," Cleaning Validation Guidelines (GUIDE-2008), US Food and Drug Administration (FDA), Office of Regulatory Affairs, Washington, DC, USA, 2011.

[8] E. Chu and A. C. Sartorelli, "Cancer chemotherapy," in Basic and Clinical Pharmacology, B. G. Katzung, Ed., pp. 949-975, McGraw-Hill, New York, NY, USA, 12th edition, 2012.

[9] R. Hrdina, V. Gersl, I. Klimtová, T. Simůnek, J. Machácková, and M. Adamcová, "Anthracycline-induced cardiotoxicity.", Acta Medica, vol. 43, no. 3, pp. 75-82, 2000.

[10] J. M. Horacek, R. Pudil, L. Jebavy, M. Tichy, P. Zak, and J. Maly, "Assessment of anthracycline-induced cardiotoxicity with biochemical markers," Experimental Oncology, vol. 29, no. 4, pp. 309-313, 2007.

[11] J. M. Horacek, M. Vasatova, M. Tichy, R. Pudil, L. Jebavy, and J. Maly, "The use of cardiac biomarkers in detection of cardiotoxicity associated with conventional and high-dose chemotherapy for acute leukemia," Experimental Oncology, vol. 32 , no. 2, pp. 97-99, 2010. 
[12] J. Hartl, M. Doležal, M. Miletín et al., Pharmaceutical Chemistry IV, Charles University, Prague, Czech Republic, 2006.

[13] O. O. Shevchuk, E. A. Posokhova, L. A. Sakhno, and V. G. Nikolaev, "Theoretical ground for adsorptive therapy of anthracyclines cardiotoxicity," Experimental Oncology, vol. 34, no. 4, pp. 314-322, 2012.

[14] T. Šimůnek, M. Štěrba, O. Popelová, M. Adamcová, R. Hrdina, and V. Gerši, "Anthracycline-induced cardiotoxicity: overview of studies examining the roles of oxidative stress and free cellular iron," Pharmacological Reports, vol. 61, no. 1, pp. 154171, 2009.

[15] A. Walsh, "Cleaning validation for the 21st century: acceptance limits for active pharmaceutical ingredients (APIs): Part I," Pharmaceutical Engineering, vol. 31, no. 4, pp. 78-83, 2011.

[16] ICH, "ICH harmonised tripartite guideline, Q2A, text on validation of analytical procedures," in Proceedings of the International Conference on Harmonisation of Technical Requirements for Registration of Pharmaceuticals for Human Use, October 1994. 

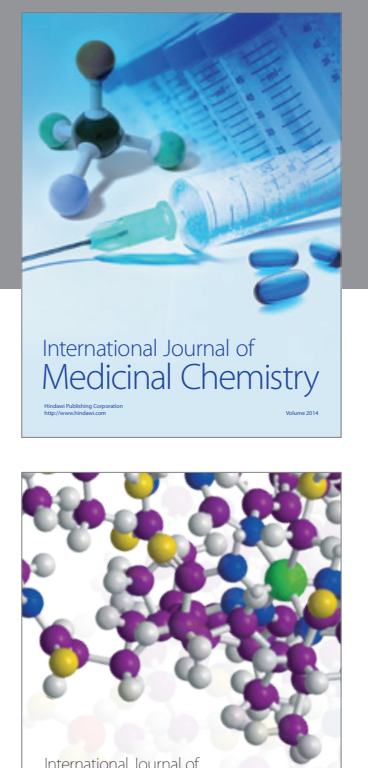

\section{Carbohydrate} Chemistry

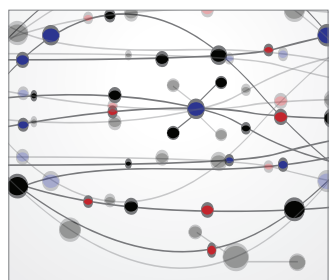

The Scientific World Journal
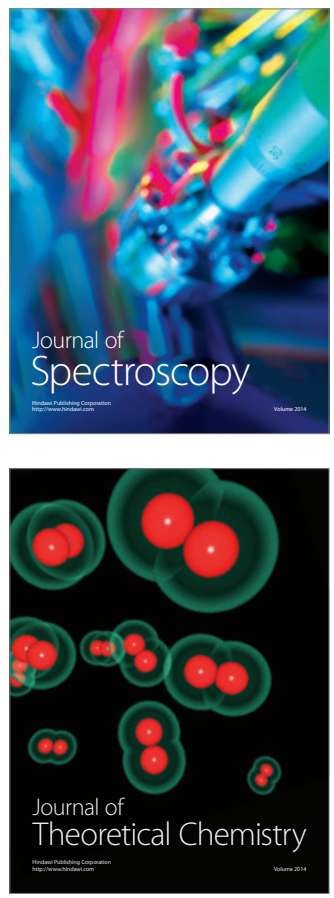
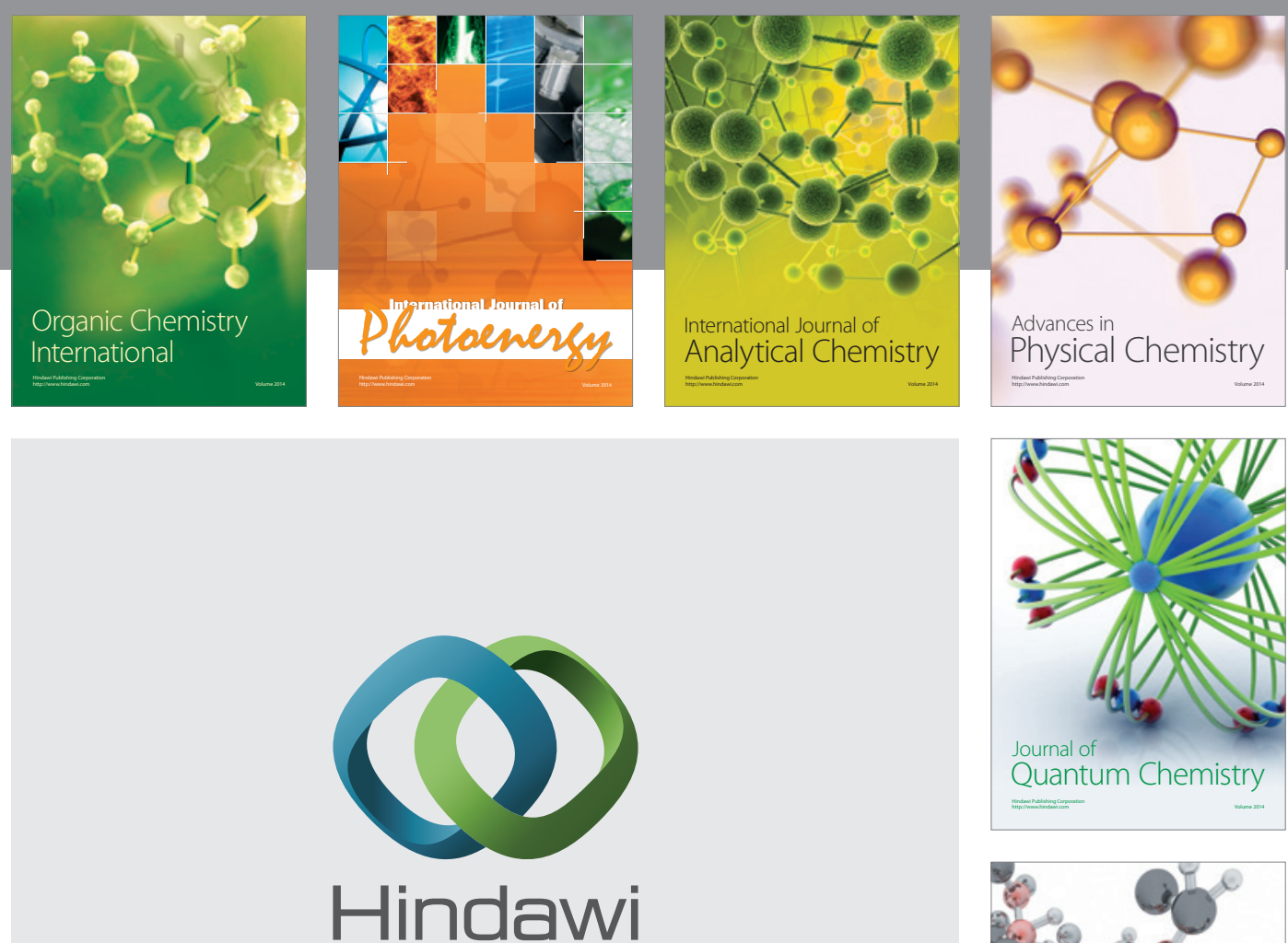

Submit your manuscripts at

http://www.hindawi.com

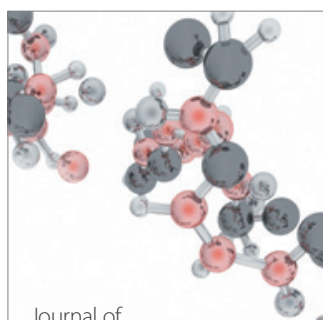

Analytical Methods

in Chemistry

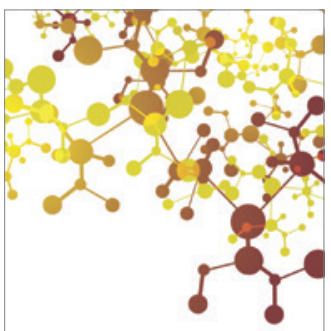

Journal of

Applied Chemistry

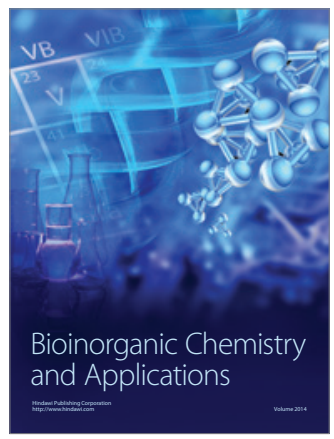

Inorganic Chemistry
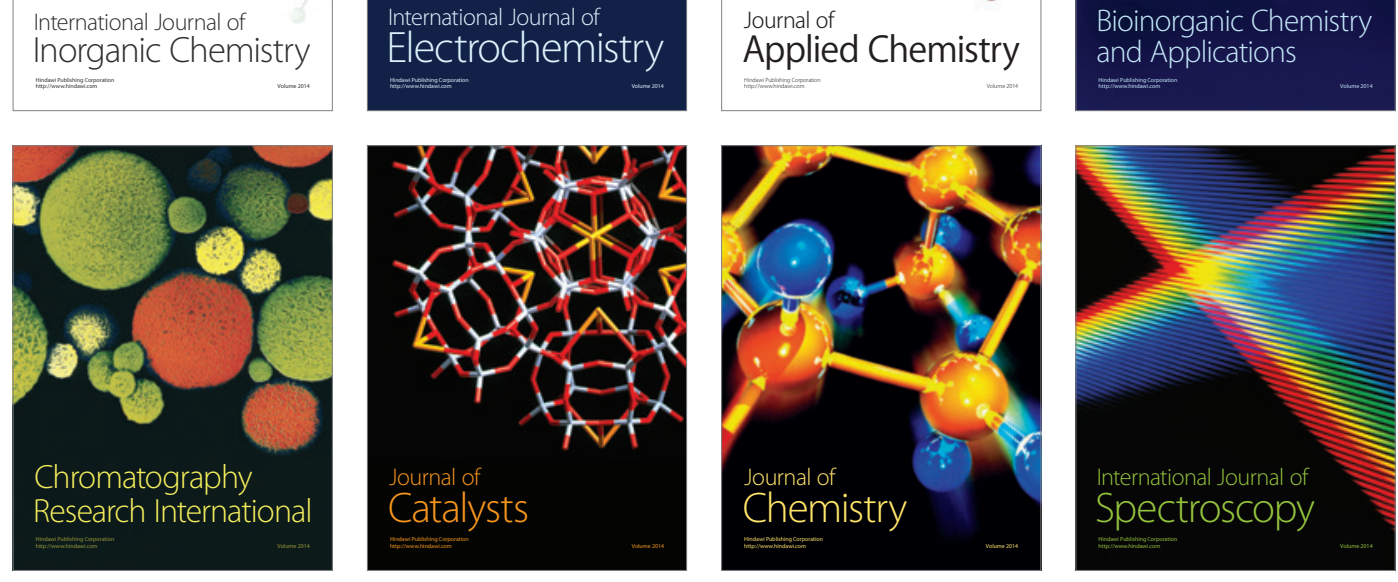